\title{
Spatial and Temporal Variations in Secondary Metabolites Content of the Brazilian Arnica Leaves (Lychnophora ericoides Mart., Asteraceae)
}

\author{
Leonardo Gobbo-Neto, Anelize Bauermeister, Humberto T. Sakamoto, \\ Dayana R. Gouvea, João Luis C. Lopes and Norberto P. Lopes*
}

\author{
Núcleo de Pesquisa em Produtos Naturais e Sintéticos (NPPNS), \\ Faculdade de Ciências Farmacêuticas de Ribeirão Preto, \\ Universidade de São Paulo, 14040-903 Ribeirão Preto-SP, Brazil
}

\begin{abstract}
The genus Lychnophora (Asteraceae) is a medicinal plant traditionally used as anti-inflammatory or analgesic agent. Its biological properties have been widely investigated and correlated with its chemical composition, which could be different between the species and even accordingly to the place and season of collection. In this work, it was investigated the spatial and temporal variations in the secondary metabolites from five populations of Lychnophora ericoides. Among them, a more diversified secondary metabolism was observed for the plants collected at Ibiraci-MG (Brazil), a city placed between two biomes, Cerrado and Atlantic Forest. The highest concentrations of chlorogenic acids were found in the Cerrado dry season (winter), while the flavonoids were higher during the rainy season (summer). Significant reduction was observed in the contents of all the secondary metabolites in old leaves, and also in flowery branches. These variations detected in L. ericoides leaves could highly influence the intensity of the biological activities of this plant.
\end{abstract}

Keywords: Lychnophora ericoides, Asteraceae, traditional medicine, seasonal variation, secondary metabolites

\section{Introduction}

Traditional medicine was and has been widely applied around the world for promoting health, and along the history, many drugs have been isolated from medicinal plants. ${ }^{1-3}$ Due to its large size and great variety of climate and biomes, Brazil has a high biodiversity popularly used to treat different diseases. ${ }^{4,5}$ These biological properties are attributed to the secondary metabolite contents, which are ecologically important for the plant to protect against solar radiation, and microbial and herbivore attacks. ${ }^{6,7}$ Their accumulation in plants is described in the literature, as being influenced by changes in the environmental conditions, such as temperature, sunlight, water availability, pollution, nutrients, herbivore and microbial attacks and others. ${ }^{8-10} \mathrm{As}$ a strategy to adapt and survive under damaging conditions, plants use many complex biochemical processes to create chemical defense mechanisms, and this behavior cannot be neglected in pharmacology of medicinal plants. Thus, there are many phytochemical studies evaluating seasonal effects in the bioactive secondary metabolite production, ${ }^{11-13}$ and

*e-mail: npelopes@fcfrp.usp.br relating their importance to the environment, ${ }^{8}$ to understand the behavior of these plants.

The genus Lychnophora (from Asteraceae family) is a plant endemic in Brazil, that has been used as a prospective source of natural products. ${ }^{14}$ This plant usually grows in the Cerrado, where are found only few arboreous and herbaceous species. ${ }^{15}$ Some species of Lychnophora are extensively used in traditional Brazilian herbal medicine as anti-inflammatory, as well as analgesic, antimicrobial and anti-rheumatism agent. ${ }^{16}$ More specifically, L. ericoides, known as "arnica da serra" or "falsa arnica", is popularly used orally for medical purposes in the form of hydroalcoholic extracts prepared by macerating its leaves with cachaça ("aguardente"). ${ }^{17}$

Terpenoids (70.2\%) (mainly sesquiterpene lactones) and flavonoids (16.9\%) are the main groups of secondary metabolites reported in the literature for Lychnophora species, followed by chlorogenic acids and their derivatives (5.0\%) and others. ${ }^{14}$ Pharmacological studies of secondary metabolites from $L$. ericoides have reported vicenin-2 and di-caffeoylquinic acids as responsible for the anti-inflammatory and analgesic activities of the hydroalcoholic extracts used in popular medicine. ${ }^{18-20}$ 
Differently from other Lychnophora species used in Brazilian popular medicine, chalcones were detected only in L. ericoides. ${ }^{17}$

During several field expeditions, the local collector reported the occurrence of some conditions to obtain more active leaves. ${ }^{21}$ This information stimulated the present work looking for the investigation of possible occurrence of variations in secondary metabolite contents relative to seasonal and spatial effects, from leaves of the Brazilian arnica Lychnophora ericoides Mart. (Asteraceae) by HPLC-DAD (high-performance liquid chromatography with diode array detection). More specifically, the content of flavonoids, sesquiterpene lactones and chlorogenic acids were evaluated, and the correlation between them was discussed.

\section{Experimental}

\section{Chemicals}

The organic solvents employed in this study were HPLC grade methanol $(\mathrm{MeOH})$, acetonitrile $(\mathrm{MeCN})$ and acetic acid obtained from JT Baker, and ultrapure water (18 $\mathrm{m} \Omega \mathrm{cm}$, Milli-Q; Millipore). The coumarin used as HPLC internal standard (IS) was purchased from Merck.

\section{Instrumentation}

The analyses were developed on a Shimadzu LC-6AD apparatus with a diode array detector (SPD-M10Avp, Shimadzu), coupled with an auto injector (SIL-10AF, Shimadzu). To data acquisition, the CLASS-VP 6.14 software was used. Chromatographic separation was carried out on a HypersilLC-18 column $(5 \mu \mathrm{m}, 4.6 \times 250 \mathrm{~mm}$, Sigma-Aldrich) coupled to a guard column $(4.6 \times 10.0 \mathrm{~mm})$ of equivalent material. To peak identification, the analyses were performed on a mass spectrometer UltrOTOFq (Bruker Daltonics) ESI-qTOF (electrospray ionizationquadrupole time of flight analyzer), accordingly to Gobbo-Neto and Lopes. ${ }^{17}$

\section{Plant materials}

It was collected branches of ten individuals (I to X) from five different populations of $L$. ericoides Mart (1-5). They were monthly collected, during 24 months starting in April 2000, by Prof Dr Leonardo Gobbo-Neto and Prof Dr Norberto P. Lopes at (i) Ibiraci-MG (NPL284; S $20^{\circ} 20^{\prime} 04.6^{\prime \prime}$, W $047^{\circ} 08^{\prime} 22.9^{\prime \prime}, 1090 \mathrm{~m}$ altitude), (ii) Delfinópolis-MG (NPL123; S 20²0' 55.0", W 046 47' 63.8", $870 \mathrm{~m}$ altitude), (iii) São João Batista do Glória-MG (NPL221;
S $20^{\circ} 37^{\prime} 54.0^{\prime \prime}, \mathrm{W} 046^{\circ} 19^{\prime} 39.1^{\prime \prime}, 900 \mathrm{~m}$ altitude), (iv) Capitólio-MG (NPL225; S 20 42' 10.7", W 046 17' 33.6", $1090 \mathrm{~m}$ altitude), and (v) São José da Barra-MG (NPL227; S 20³8' 31.6", W 046 15' 31.8", $1010 \mathrm{~m}$ altitude) and identified by Prof Dr João Semir, Departamento de Botânica, Instituto de Biologia (Unicamp), Brazil.

\section{General experimental procedure}

The samples used for intra and inter-populational analysis and also for seasonal effects were prepared as follow: young leaves up to $10 \mathrm{~cm}$ from the top of each branch (without flowers) were collected, dried at drying oven and milled together. Samples were prepared by extraction with methanol:water $(9: 1)$ according to Gobbo-Neto and Lopes. ${ }^{17}$

Coumarin was used as internal standard. All samples were analyzed by liquid chromatography using a validated methodology for L. ericoides leaves described by Gobbo-Neto and Lopes. ${ }^{17}$ In the cited work, the authors described 52 chromatographic peaks for leaves of $L$. ericoides, and identified 36 of them by mass spectrometric data. ${ }^{17}$ This information was used in this work as comparisons between the secondary metabolite contents, which were undergone based on relative areas (peak area / IS area) obtained for each peak by Gobbo-Neto and Lopes. ${ }^{17}$ Graphics were built with the average population of each metabolite.

The relative areas were used in equations obtained from the calibration curve, ${ }^{17}$ determining the relative concentration of the metabolites as $\mu \mathrm{gL}^{-1}$ in the analyzed extract. This concentration was converted into percentage by multiplying the relative concentration by 0.3 (the crude extract was prepared in $3 \mathrm{~mL}$ ) and the obtained value was divided by 20 (it was used $20 \mathrm{mg}$ of the vegetal material to the extraction).

Intra-individual variations were evaluated by comparison between: (i) leaves from different branches from a same individual; (ii) young and old leaves from the same branch; and (iii) branches with and without flowers. Intra and inter-population variations were also evaluated by comparison of secondary metabolite contents between individuals from different populations. The inter-population variation was considered in the choice of samples to be evaluated for seasonal effect.

To evaluate the seasonal effect on the relative concentration of the metabolites, samples were monthly collected, during 24 months for 1-III, 2-IV, 3-VI, 4-I and 5-VIII and during 15 months for 1-X and 2-I. Graphics were built with the monthly variation of secondary metabolites and clustered by classes (flavonoids, chlorogenic acids and sesquiterpene lactone (STL)). $C$-Glucosylflavones and 
coumaroyl-glycosyl-flavonols were considered as separate groups from aglycone flavonoids.

\section{Statistical analyses}

To proceed the statistical analyses of hierarchical cluster analysis (HCA), the values included in the spreadsheet were standardized to equalize the data for all metabolites. Thus, the value 0 was assigned for absent peaks, 10 for major peaks and 5 for trace peaks. This new spreadsheet was submitted to HCA (L. ericoides samples) depending on the variables (metabolites concentration) using the Ward method. ${ }^{22}$ The analyses were conducted in the software Statistica (version 7.0, StatSoft Inc.).

\section{Results and Discussion}

To ensure that the collected sample would be really representative of a metabolic situation of all plant leaves, it was evaluated some possible intra-individual variation in the secondary metabolite contents, as well as their range. Only quantitative variations were observed between two branches for each evaluated individual (Figure S1 in the Supplementary Information (SI) section). These variations are most between 10 to $15 \%$, in which the major observed variation was around $20 \%$. The determination of the metabolic variation is important to seasonal or population metabolic study to determine a limit of metabolic content variation between different branches in a single plant. ${ }^{8}$ Thus, it was assumed that variations lower than $20 \%$ could be related to an intra-individual variation which should not be considered. However, any variation higher than this level is significant.

The age and the development of the plant are also considered important factors to influence the total metabolites. ${ }^{23}$ Leave aging (bottom branches) results in a pronounced decrease in the secondary metabolite contents, compared with young leaves (apical branches) (Figure 1), mainly for chlorogenic acids and flavonoids (60 to 85\%) (Figure S2a in the SI section). Such variation is widely described in the literature, and it may occur in different classes of secondary metabolites, including those typical in L. ericoides as STL, flavonoid and phenolic acids. The high reduction rate for flavonoids and chlorogenic acid contents in old leaves may be due to a greater accumulation of these metabolites for recycling, once that to protect the plant from solar radiation effects, these metabolites are more needed in young leaves than in leaves in atrophy process. ${ }^{23-25}$ Moreover, it was related in Helianthus genus, for instance, that STLs are produced mainly in the beginning of the leave development, when they are found in high concentrations. Posteriorly, as a natural developing process, the leaves grow, diluting STL (maintaining the total content). ${ }^{26,27}$ These quantitative differences between old and young leaves have no significant influence in the temporal variation results of this study, considering that for sample preparation, all leaves of a branch are milled together. Moreover, the purpose of this study was to determine the individual variation as total, once it is unfeasible to select only young leaves rather than old in the collected plant for its medicinal use.

The flowering in L. ericoides emerges in the apical of many branches mainly in summer, between December and March, rainy season in the Cerrado. In this period, it was observed (Figure S2b in the SI section) a decrease of all metabolites in the collected flowered branches, which could be explained by resource allocation for flowering protection and development in those branches. ${ }^{23}$ The observed media variation is between 23 to $50 \%$, therefore variation is not as pronounced as those observed between young and old leaves.

The observed metabolic profile is very similar between all individuals analyzed for each population, some minor quantitative differences exist, but not qualitative. The only observed exception was in the individuals VII from population 1, and I, II and III from population 4. In 1-VII, it was not detected five of all STL identified in the other samples; and only in 4-I, 4-II and 4-III, it was found the STL centratherin (peak 27) ${ }^{17}$ in appreciable amount (results not shown). It was observed significant qualitative differences between individuals from different populations. The main difference observed between populations is the existence of a secondary metabolism much more diversified in population 1 from Ibiraci, which presents a lot of peaks that are absent in the other populations. Nearly all of the metabolites identified among the individuals of L. ericoides analyzed in this study were present in plants from population 1 .

Nevertheless, it was observed a substantial inter-population variation for STL (Figure 2a). Except for centratherin in the population 4 , discussed before, the other STLs were detected only in the population 1. All derivatives of chlorogenic acids were found, at least as traces, in all individuals; however, they were detected at greater amount in population 1 (Figure 2b). The population 3 presented intermediate level of chlorogenic acids, and population 2, the lower concentration. For flavonoids, it was not observed significant variations (Figure 2c). However, the peak 52, a not identified flavonoid, ${ }^{17}$ was found only in the population 2 , in all of the individuals. Population 2 also showed the greater amount of 3-O-methyl-quercetin and pinobanksin, and 


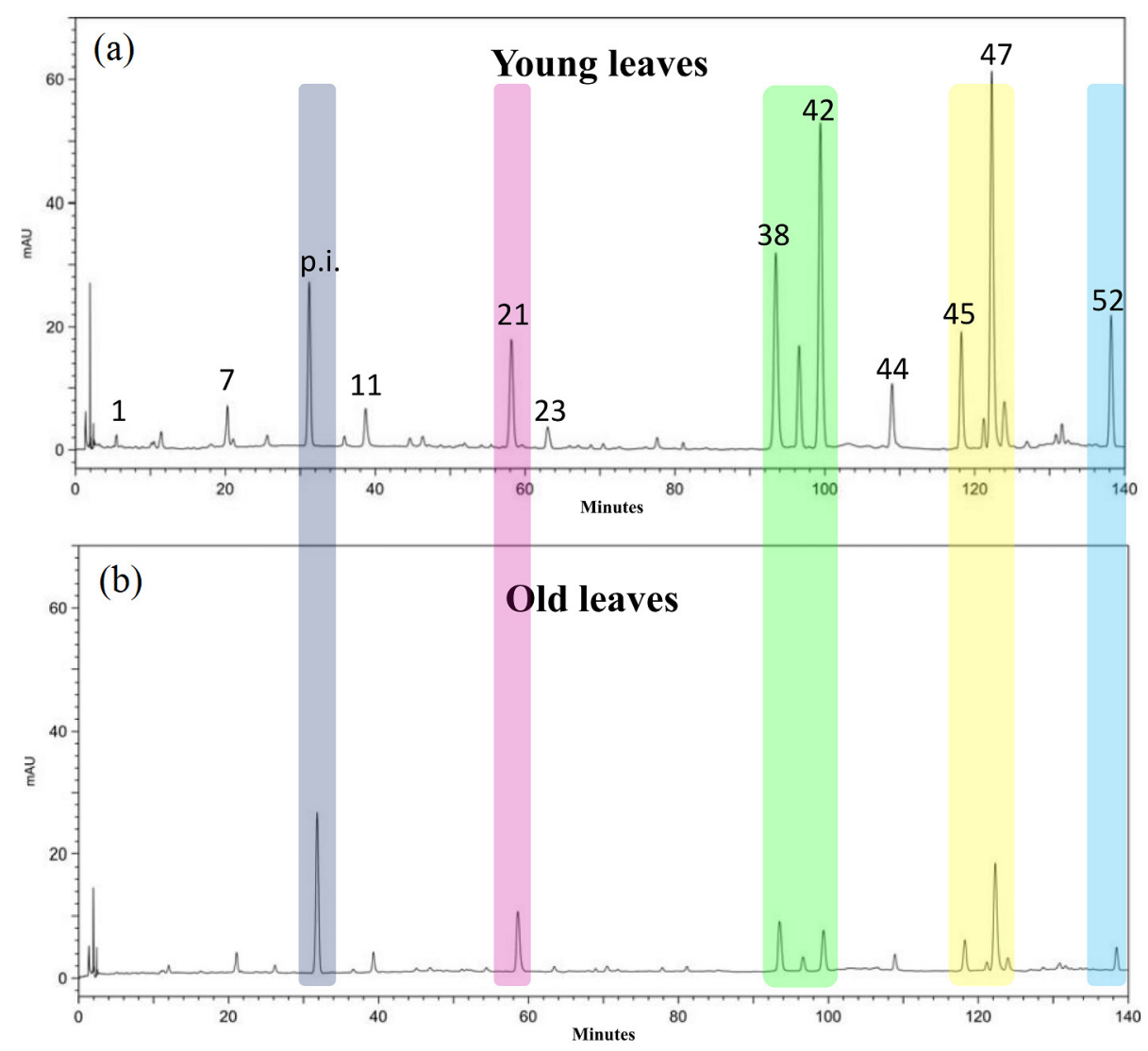

Figure 1. Chromatograms $(270 \mathrm{~nm}$ ) illustrating the quantitative variation of secondary metabolites between (a) young and (b) old leaves from the same branch of the individual 2-IV. The compounds are listed accordingly to Gobbo-Neto and Lopes. ${ }^{17}$

the only one that was not detected coumaroyl-glycosylflavonols (peaks 28 and 29). $C$-Glucosylflavones (peaks 5, 7 and 9) were detected in high concentrations in population 1.

Studies of secondary metabolite variations are very important to set potential chemical markers to determine species or genus, serving as an additional character to chemotypes determination. To date, STLs from the furanoheliangolide type have been considered as characteristic metabolite and chemotaxonomic marker of subtribe Lychnophorineae due to its isolation from plants of some genus of this subtribe. ${ }^{28-30}$ However, as can be observed in these results, STLs cannot be considered as chemotaxonomic markers, at least for the species L. ericoides, due to being detected in only one population. Nevertheless, they could be considered as characteristic of a chemotype into the species L. ericoides. This proposal can be enhanced by the STL absence in phytochemical studies with other species from the Lychnophora genus. ${ }^{31}$ In the other hand, the chlorogenic acids are present in all individual of the evaluated L. ericoides,${ }^{17,32}$ and for this reason, they could be considered as characteristic metabolite for this species; however, the widespread occurrence in Asteraceae family ${ }^{8,33,34}$ limits its use as a chemotaxonomic marker.
Besides the inter-population variations discussed before, in all populations, most flavonoids are the same and occur at similar amounts. These metabolites should be considered as characteristic secondary metabolites of $L$. ericoides, along with the chlorogenic acids. The wide variety of skeleton types and substitution patterns in flavonoids could be used to distinguish between taxa and chemotypes, being important chemical markers. ${ }^{35-37}$ It is possible to note in L. ericoides, a predominance of flavanones and its isomers 5-hydroxy-chalcones and dihydro-flavonols. It is also possible to note the absence of flavones or flavonol aglycones, which are flavonoids very common in the Asteraceae family, and the presence of di-C-glucosylflavone vicenin-2 at high concentrations. Thus, the following metabolites are suggested as chemical markers to characterize the species L. ericoides: chlorogenic acids, di- $C$-glucosylflavone vicenin-2, dihydroflavonol 3-O-acethyl-pinobanksin and the flavanones pinocembrin and pinostrobin and their isomeric forms 2',4',6'-trihydroxy-chalcone and 2',6'-dihydroxy4'-methoxi-chalcone.

A theory of Prof Otto Richard Gottlieb ${ }^{38}$ can be used to try to explain the STL presence in only one population. According to this theory, plants occurring on the border 

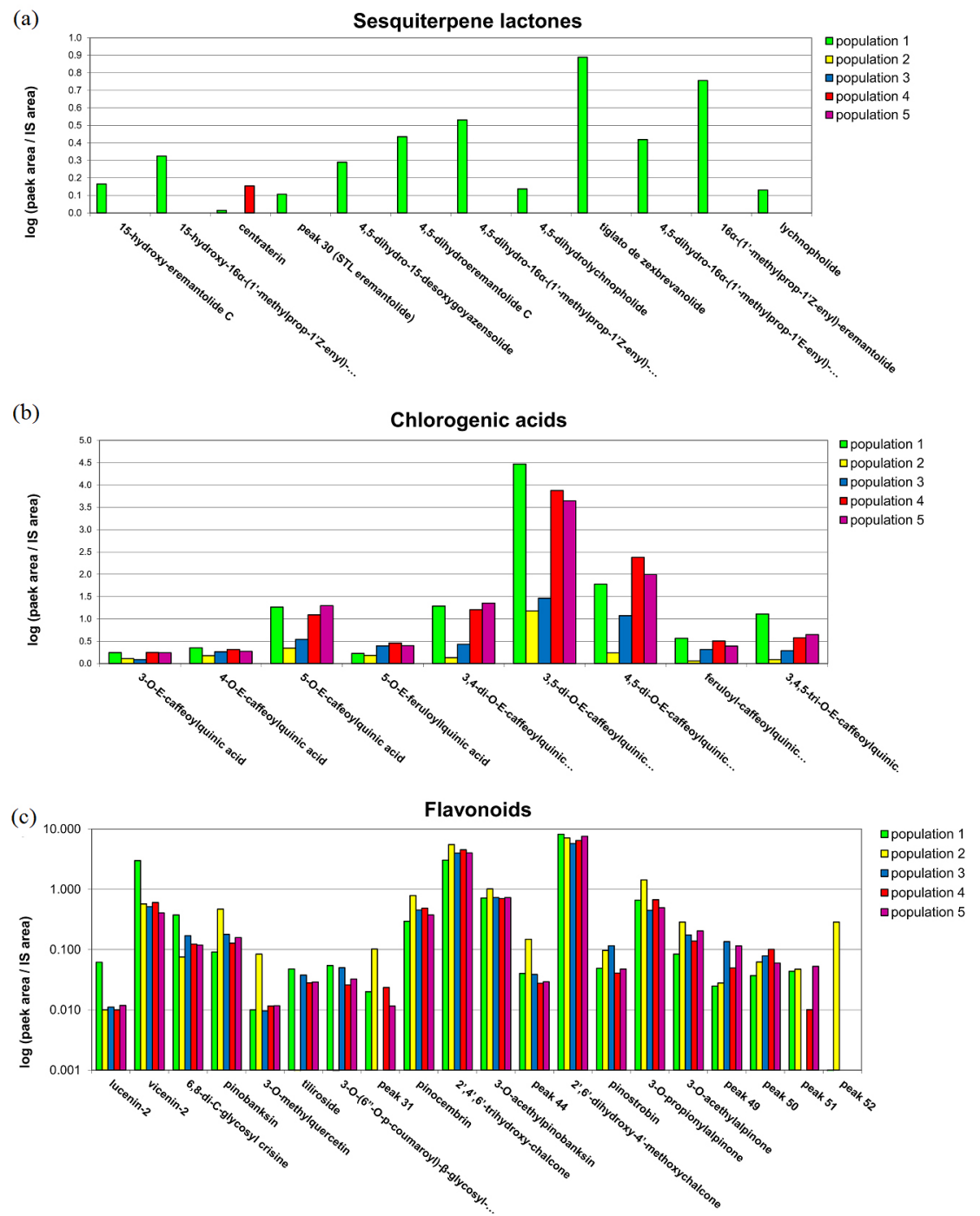

Figure 2. Inter-population variation in L. ericoides leaves for (a) sesquiterpene lactones, (b) chlorogenic acids and (c) flavonoids.

between two types of vegetation (and consequently of fauna) could be stimulated to amplify the production and storage of defensive secondary metabolites. This hypothesis can be strengthened by Gobbo-Neto et al. ${ }^{32}$ in which is reported that the extract from Ibiraci exhibited the strongest cytotoxic activity in all the evaluated cell lines, while the extracts from the other places presented insignificant or very low cytotoxicity in general. The city of Ibiraci is located in a transition area between two biomes: Cerrado and the semi-deciduous of the Atlantic Forest, while the other populations are located in inner area of the Cerrado.

To support the inter-population variation observed and discussed before, it was performed a statistical analysis of HCA for all studied individuals (Figure S3 in the SI section). It was used the relative areas obtained for metabolites of each individual (Table S1 in the SI section). This analysis separated the individuals in two groups which show between them a high degree of binding distancing (x axis): one group formed entirely by the individuals from population 1 and the other group by the remaining individuals. This result can be explained by the STL presence almost exclusively in the population 1, as discussed before. The second group was subdivided in two more groups: one consists entirely by the individuals from the population 2 and the other by the remaining individuals. The separate clustering of population 2 could be explained mainly by the absence of coumaroyl-glycosyl-flavonols, by the high concentration of 3-O-methyl-quercetin and pinobanksin. Thus, HCA also evidenced and proved the metabolic similarity between individuals from the same population, and clustered all individuals from populations 3, 4 and 5 in a single cluster.

Finally, considering all data of discussed intra- and inter-population variations, based on the differentiated secondary metabolism obtained by HCA (three main groups of L. ericoides, group 1: population 1 
(Ibiraci); group 2: population 2 (Delfinópolis), and group 3: populations 3 (São João Batista do Glória), 4 (Capitólio) and 5 (São José da Barra)), it was suggested that the groups should be considered for the following study of seasonal effects.

To evaluate the seasonal effect, it was selected individuals to represent each one of the groups obtained by HCA. The data obtained from the HPLC analysis of the sample collected for 24 months (1-III, 2-IV, 3-VI, 4-I and 5 -VIII) were used to build the graphic with the monthly variation of the major metabolite content. To facilitate the result understanding, the metabolites were grouped by classes (flavonoids, STL and chlorogenic acids).

Figure 3 shows the analysis for individual 2-IV, it can be noted that the concentration of flavonoids and chlorogenic acids exhibited pronounced inversely proportional variation to each other. Between May and September, chlorogenic acids showed the highest concentrations, while in the same period, it was observed the lowest concentrations for flavonoids. Inversely, in the other periods, the chlorogenic acid concentrations decreased around $75 \%$ and aglycone flavonoids increased $80 \%$. As chlorogenic acids and flavonoids have the same biosynthetic origin, their inversely proportional variation may indicate an intermediate deviation from phenylpropanoid pathway to preferential production of chlorogenic acids, instead the flavonoids, in winter. At governamental websites as INMET (Instituto Nacional de Meteorologia) and CPTEC/INPE (Centro de Previsão de Tempo e Estudos Climáticos), it is available information about Cerrado climate. In winter, the nights are cold and does not rain for 2 to 3 months. The rain comes back at the beginning of spring. Correlating these variations with the environmental variations from Cerrado characteristic, it is evident that the periods with high level of chlorogenic acids match the winter (water scarcity and night cold) in the Cerrado region, where the plants were collected.

The evaluated individual from population 3 (3-VI) showed a similar behavior to that observed to 2-VI (Figure 4). However, this individual showed a little difference presenting a cyclic variation in the chlorogenic acid contents: this metabolite concentration rose rapidly in August; then also reduced rapidly after the maximum and rose gradually to intermediate level in March, restarting the cycle. The cyclic repetition proves the seasonal effect in chlorogenic acids. The flavonoid class presented a more random variation than the one observed for population 2 , but still higher in the period between the maximum chlorogenic acid concentration. $C$-Glucosylflavones and coumaroyl-glycosyl-flavonols maintained constant their concentrations.

For population 4 and 5 , the observed variations concerning chlorogenic acids (Figures S4 and S5 in the SI section) were very similar to the one observed for individual 3-VI. Although the months observed with the maximum metabolite concentration were not exactly the same, in these three populations, the maximum was always observed between the months June and September; and the lower concentrations were observed between October and December. An exception to this pattern was observed for individual 4-I which shows very high chlorogenic acids concentration between November 2001 and February 2002. However, this exacerbated increase may have been due to other factors than seasonality. In that period, it was noted that their leaves were damaged and showed white spots all over its surface. This suggests some kind of pathogens

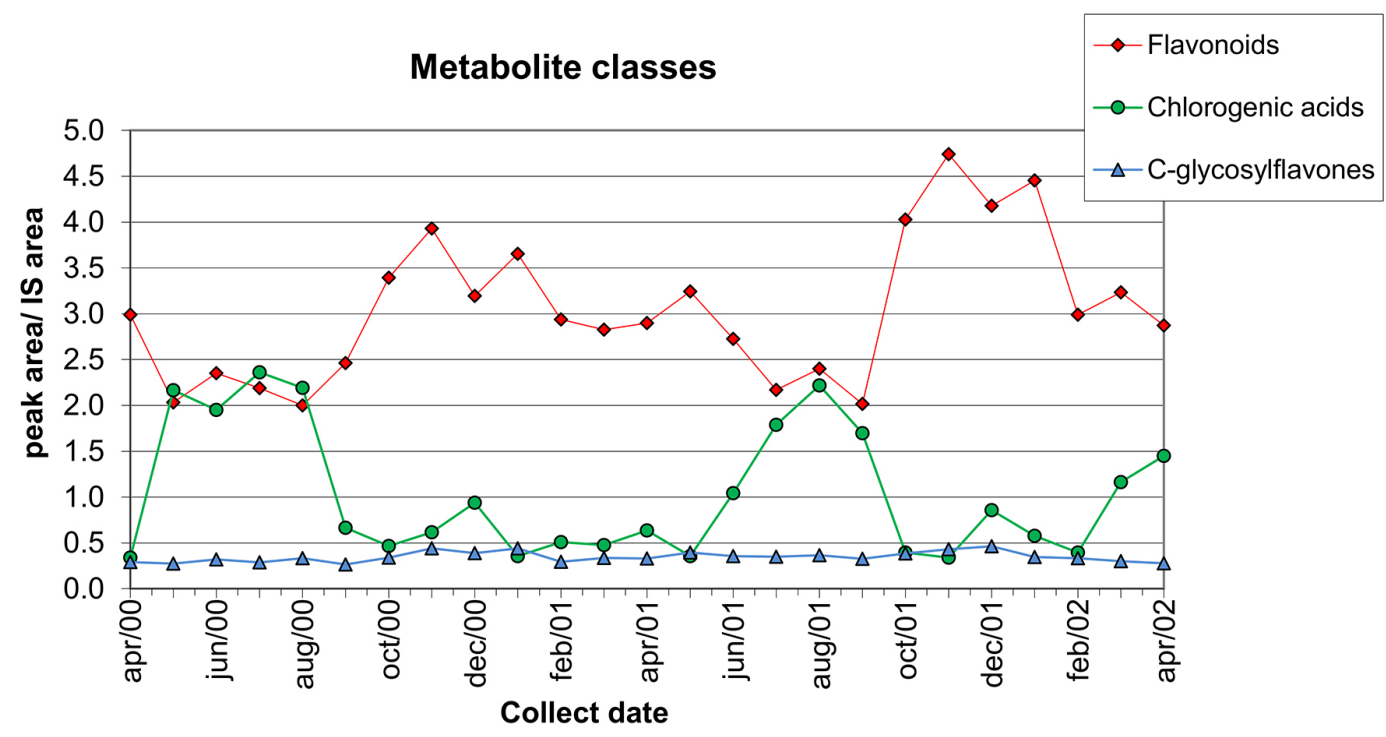

Figure 3. Seasonal variation in L. ericoides leaves in the individual 2-IV for chlorogenic acids, flavonoids and $C$-glycosylflavones. 


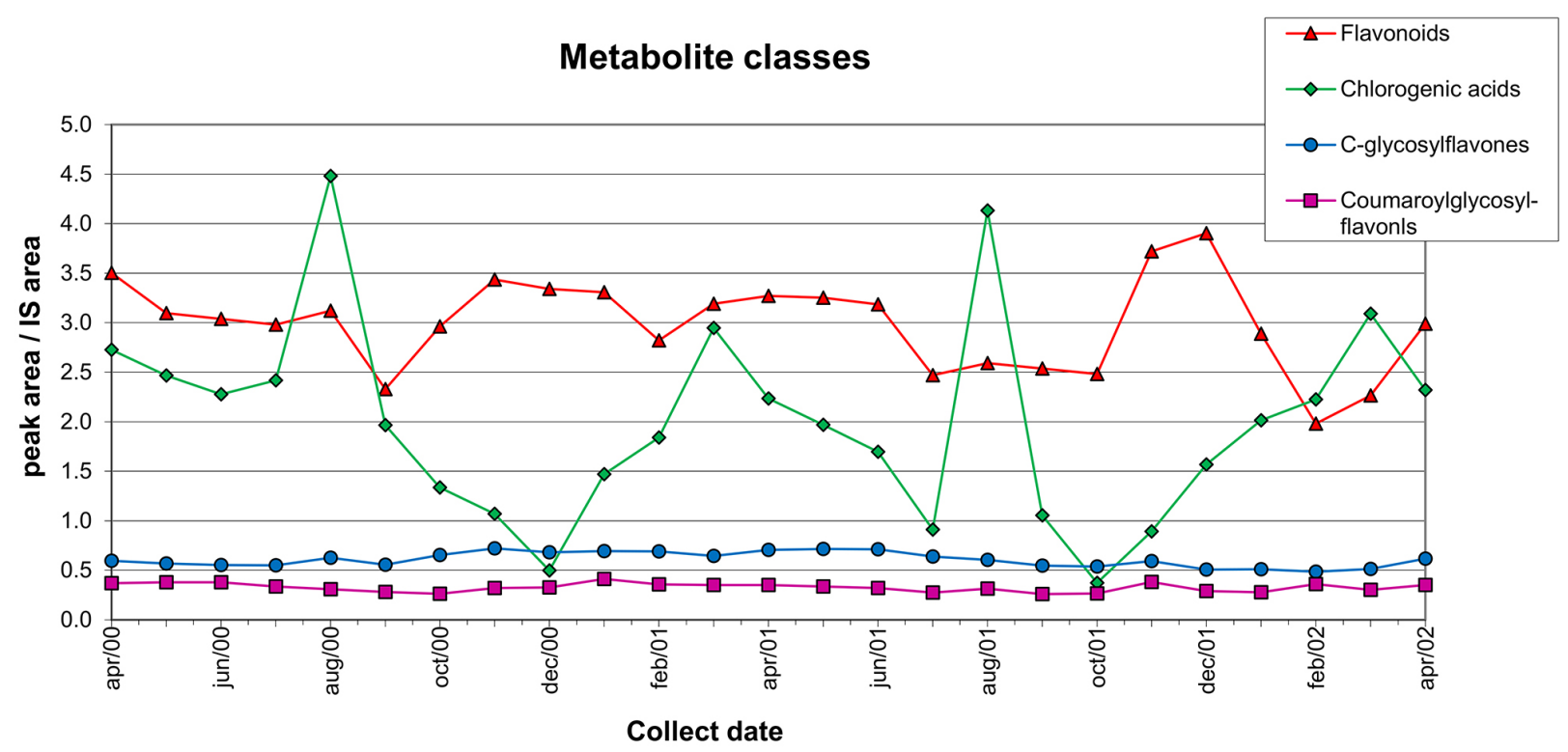

Figure 4. Seasonal variation in L. ericoides leaves in the individual 3-VI for chlorogenic acids, flavonoids, $C$-glycosylflavones and coumaroyl-glycosylflavonols.

attack and/or herbivores, and consequently, that unusual behavior may be a plant defense mechanism. In addition, this plant was the only one among the analyzed without flowers during the summer of 2001 and 2002.

Considering the range of $20 \%$ variation as significant, the individual III from population 1 did not show significant variation in total flavonoids. However, variations of 40 to $50 \%$ were observed for the majority flavonoids from this individual, especially for chalcones (Figure S6 in the SI section). About the total chlorogenic acids, it was observed a variation around $85 \%$ between maximum and minimum levels. Although this value is similar to that observed for other populations, it is not possible to identify a cyclical pattern (seasonal) for these variations being observed maximum and minimum concentration peaks in several months. This suggests that, differently from other populations, the influence of other environmental factors, rather than seasonality, are prevalent for determining the content of secondary metabolites in this population.

Overall, it was observed some points out of the pattern for chlorogenic acids in the individuals 3-IV (Feb/2001 and Mar/2002), 5-VIII (Jan/2002), 1-III (Dec/2001 and Feb/2001) and 4-I (Dec/2001). Nonetheless, they are considered occasional situations which might be justified by some climatic factor or because of herbivory induction or plant damage. ${ }^{39,40}$

Accordingly to the observed seasonal effects, it is possible to resume that: $(i)$ high concentrations of chlorogenic acids are found in winter, however they could be found in other seasons at intermediate contents, as observed to population 3, for instance; (ii) flowering plants show low concentrations of chlorogenic acids even in that plant branches without flowers; (iii) the flavonoid concentrations are usually higher during the rainy period in the Cerrado region (summer); (iv) the $C$-glucosylflavones and STL concentrations remain stable all year long, therefore, plant collection aiming these metabolites could be done at any season.

L. ericoides is popularly used in traditional medicine mainly due to its anti-inflammatory activity, and rootworkers believe that to obtain a better biological activity in the alcoholic extract, the collection must be in the flowering period. Accordingly, to the discussed secondary metabolite variation, in the flowering period, it was found in L. ericoides the lower amount of chlorogenic acids and usually the higher concentrations of flavonoids as aglycones. It was reported that among the secondary metabolites of medium and high polarity from $L$. ericoides, vicenin-2 ( $C$-glucosylflavone) and the chlorogenic acids are the ones with pronounced anti-inflammatory activity, besides STLs which are not present in most plant of this species. ${ }^{18-20,41}$

Correlating the collect period and biologic activities of the main metabolites in L. ericoides, the best period to collect would be when the plant was not flowering, considering the higher concentration of the metabolites with anti-inflammatory activity (chlorogenic acid and vicenin-2, reminding that the latter remains in constant concentration). Although, the desired anti-inflammatory activity may also be due to other low polarity metabolites unidentified yet in L. ericoides. 


\section{Conclusions}

In conclusion, temporal and spatial variations were observed for secondary metabolites from $L$. ericoides leaves. That could result in pronounced quali- and quantitative variations in the collected plant material, and can strongly influence the popularly produced extract, providing a higher or lower anti-inflammatory and/or analgesic effect than expected. Environmental characteristics directly interfered in the L. ericoides secondary metabolite contents in seven specimens from five evaluated populations, except for population from Ibiraci. The populations showed one or more seasonal behavior difference due to environmental differences. Chlorogenic acid and flavonoid maxima productions could be correlated with the dry and rainy seasons of Cerrado biome. C-Glycosyl-flavonoid, coumaroyl-glucosylflavonoid and STL contents were constant year round.

\section{Supplementary Information}

Graphics about intra-individual variation, variations between young and old leaves, and seasonal variation of individuals discussed in the paper are available as supplementary data free of charge at http://jbcs.sbq.org.br as PDF file.

\section{Acknowledgments}

The authors thank the financial support from São Paulo Research Foundation (FAPESP) under grant agreements 2014/20302-4 and 2014/50265-3, CAPES and CNPq (No. 150056/2016-8).

\section{References}

1. González-Tejero, M. R.; Martínez-Lirola, M. J.; Casares-Porcel, M.; Molero-Mesa, J.; Econ. Bot. 1995, 49, 96.

2. Lopez-Rubalcava, C.; Estrada-Camarena, E.; J. Ethnopharmacol. 2016, 186, 377.

3. Repetto, M. G.; Llesuy, S. F.; Braz. J. Med. Biol. Res. 2002, 35, 523.

4. Trojan-Rodrigues, M.; Alves, T. L. S.; Soares, G. L. G.; Ritter, M. R.; J. Ethnopharmacol. 2012, 139, 155.

5. Martins, J. L. R.; Rodrigues, O. R. L.; de Sousa, F. B.; Fajemiroye, J. O.; Galdino, P. M.; Florentino, I. F.; Costa, E. A.; Fundam. Clin. Pharmacol. 2015, 29, 238.

6. Boege, K.; Marquis, R. J.; Trends Ecol. Evol. 2005, $20,441$.

7. Barton, K. E.; Boege, K.; Ecol. Lett. 2017, 20, 403.

8. Gouvea, D. R.; Gobbo-Neto, L.; Sakamoto, H. T.; Lopes, N. P.; Lopes, J. L. C.; Meloni, F.; Amaral, J. G.; Quim. Nova 2012, $35,2139$.
9. Kim, N. K.; Park, H. M.; Lee, J.; Ku, K.-M.; Lee, C. H.; J. Agric. Food Chem. 2015, 63, 8631.

10. El Morchid, M.; Londoño, P. T.; Papagiannopoulos, M.; Gobbo-Neto, L.; Müller, C.; Biochem. Syst. Ecol. 2014, 53, 81.

11. Chaves, T. P.; Santana, C. P.; Véras, G.; Brandão, D. O.; Felismino, D. C.; Medeiros, A. C. D. M.; Trovão, D. M. D. B. M.; Afr. J. Biotechnol. 2013, 12, 847 .

12. Mohammadi, A.; Sani, T. A.; Ameri, A. A.; Imani, M.; Golmakani, E.; Kamali, H.; Pharmacogn. Res. 2015, 7, 329.

13. Pacifico, S.; Galasso, S.; Piccolella, S.; Kretschmer, N.; Pan, S.-P.; Marciano, S.; Bauer, R.; Monaco, P.; Food Res. Int. 2015, 69, 121.

14. Keles, L. C.; de Melo, N. I.; Aguiar, G. D. P.; Wakabayashi, K. A. L.; Carvalho, C. E. D.; Cunha, W. R.; Miller Crotti, A. E.; Lopes, J. L. C.; Lopes, N. P.; Quim. Nova 2010, 33, 2245.

15. Forzza, R. C. E. A.; Catálogo de Fungos e Plantas do Brasil; Instituto de Pesquisas Jardim Botânico do Rio de Janeiro: Rio de Janeiro, Brasil, 2010

16. Cerqueira, M. D. B. E. S.; Souza, J. T. D.; Amado Junior, R.; Peixoto, A. B. F.; Cienc. Cult. 1987, 39, 551.

17. Gobbo-Neto, L.; Lopes, N. P.; J. Agric. Food Chem. 2008, 56, 1193.

18. Gobbo-Neto, L.; Santos, M. D.; Kanashiro, A.; Almeida, M. C.; Lucisano-Valim, Y. M.; Lopes, J. L. C.; Souza, G. E. P.; Lopes, N. P.; Planta Med. 2005, 71, 3.

19. Santos, M. D.; Gobbo-Neto, L.; Albarella, L.; Souza, G. E. P.; Lopes, N. P.; J. Ethnopharmacol. 2005, 96, 545.

20. Rastrelli, L.; Saravia, A.; Hernandez, M.; de Simone, F.; Pharm. Biol. 1998, 36, 315.

21. Semir, J.; Rezende, A. R.; Monge, M.; Lopes, N. P.; As Arnicas Endêmicas das Serras do Brasil - Uma Revisão sobre a Biologia e a Química das Espécies de Lychnophora (Asteraceae); UFOP: Ouro Preto, MG, Brasil, 2011.

22. Ward, J. H.; J. Am. Stat. Assoc. 1963, 58, 236.

23. Gobbo-Neto, L.; Lopes, N. P.; Quim. Nova 2007, 30, 374.

24. Grace, S. C.; Logan, B. A.; Philos. Trans. R. Soc. London, Ser. B 2000, 355, 1499.

25. Hartmann, T.; Entomol. Exp. Appl. 1996, 80, 177.

26. Hendriks, H.; Anderson-Wildeboer, Y.; Engels, G.; Bos, R.; Woerdenbag, H. J.; Planta Med. 1997, 63, 356.

27. Spring, O.; Bienert, U.; J. Plant Physiol. 1987, 130, 441.

28. Zdero, C.; Bohlmann, F.; Plant Syst. Evol. 1990, 171, 1.

29. Sakamoto, H. T.; Gobbo-Neto, L.; Cavalheiro, A. J.; Lopes, N. P.; Lopes, J. L. C.; J. Braz. Chem. Soc. 2005, 16, 1396.

30. Borella, J. C.; Lopes, J. L. C.; Vichnewski, W.; Cunha, W. R.; Herz, W.; Biochem. Syst. Ecol. 1998, 26, 671.

31. Chicaro, P.; Pinto, E.; Colepicolo, P.; Lopes, J. L. C.; Lopes, N. P.; Biochem. Syst. Ecol. 2004, 32, 239.

32. Gobbo-Neto, L.; Guaratini, T.; Pessoa, C.; Moraes, M. O. D.; Costa-Lotufo, L. V.; Vieira, R. F.; Colepicolo, P.; Lopes, N. P.; J. Braz. Chem. Soc. 2010, 21, 750. 
33. Clifford, M. N.; J. Sci. Food Agric. 1999, 79, 362.

34. Clifford, M. N.; J. Sci. Food Agric. 2000, 80, 1033.

35. Wilt, F. M.; Miller, G. C.; Biochem. Syst. Ecol. 1992, 20, 53.

36. Ferreres, F.; Tomás-Llorente, F.; Tomás-Barberán, F. A.; Rivera, D.; Obon, C.; Z. Naturforsch. 1989, 44, 568.

37. Harbonrne, J. B.; Boardley, M.; Linder, H. P.; Phytochemistry 1985, 24, 273.

38. Gottlieb, O. R.; Kaplan, M. A. C.; Borin, M. R. M. B.; Biodiversidade: um Enfoque Químico-Biológico; Editora UFRJ: Rio de Janeiro, Brasil, 1996.
39. Rani, P. U.; Sambangi, P.; Sandhyarani, K.; J. Insect Behav. 2017, 30, 16.

40. Wang, L. J.; Qu, L. J.; Hu, J. J.; Zhang, L. W.; Tang, F.; Lu, M. Z.; Environ. Exp. Bot. 2017, 136, 31.

41. Santos, M. D. D.; Chen, G.; Almeida, M. C.; Soares, D. M.; de Souza, G. E. P.; Lopes, N. P.; Lantz, R. C.; Nat. Prod. Commun. 2010, 5, 733.

Submitted: February 1, 2017

Published online: May 25, 2017 